REVIEW

\title{
Interventional radiology in the elderly
}

\author{
Konstantinos Katsanos \\ Farhan Ahmad \\ Renato Dourado \\ Tarun Sabharwal \\ Andreas Adam \\ Department of Interventional \\ Radiology, Guy's and St.Thomas' \\ Hospital, NHS Foundation Trust, \\ London, UK
}

\begin{abstract}
Interventional radiological percutaneous procedures are becoming all the more important in the curative or palliative management of elderly frail patients with multiple underlying comorbidities. They may serve either as alternative primary minimally invasive therapies or adjuncts to traditional surgical treatments. The present report provides a concise review of the most important interventional radiological procedures with a special focus on the treatment of the primary debilitating pathologies of the elderly population. The authors elaborate on the scientific evidence and latest developments of thermoablation of solid organ malignancies, palliative stent placement for gastrointestinal tract cancer, airway stenting for tracheobronchial strictures, endovascular management of aortic and peripheral arterial vascular disease, and cement stabilization of osteoporotic vertebral fractures. The added benefits of high technical and clinical success coupled with lower procedural mortality and morbidity are highlighted.
\end{abstract}

Keywords: elderly, radiofrequency ablation, stents, aortic endografts, angioplasty, vertebroplasty

\section{Introduction}

Interventional radiology is a clinically-oriented specialty that employs image guidance in order to perform minimally invasive diagnostic and therapeutic procedures. ${ }^{1}$ Technological developments of imaging equipment coupled with the advanced engineering of pinhole therapeutic applicators and minuscule endovascular instruments have fuelled worldwide adoption of transcatheter and percutaneous techniques in the treatment of various vascular and solid organ pathologies with increased efficacy and reduced rates of morbidity and mortality. ${ }^{2}$

Elderly patients may be poor anesthetic candidates and are usually denied surgical treatments because of underlying comorbidities. In addition, elderly patients are in a higher risk of developing peri- and post-operative complications and usually require a longer and more cost-consuming recovery and rehabilitation period. Moreover, there is decreased pain sensitivity and perception with aging, which may further complicate therapy and management of the geriatric population. Elderly cancer patients, in particular, may suffer from increased drug toxicity and peri-operative morbidity and mortality because of age-related physiological decline and reduced functional reserve capacity. ${ }^{3-6}$

Front-line minimally invasive therapeutic procedures that are alternatives or may serve as adjuncts to traditional surgical treatments are becoming all the more important in the curative or palliative management of elderly frail patients with multiple comorbid conditions. The present report provides a concise review of several interventional radiological-guided procedures with a special focus on the treatment of the primary debilitating pathologies of the elderly population. In particular, the authors elaborate on thermoablation of solid organ malignancies, palliative stent placement for gastrointestinal tract cancer, endovascular management of aortic and peripheral arterial vascular disease, and cement stabilization of osteoporotic vertebral fractures (Figure 1). However, interventional radiological procedures in the elderly further include and are not limited to hepatobiliary interventions in malignancy, percutaneous urinary tract 


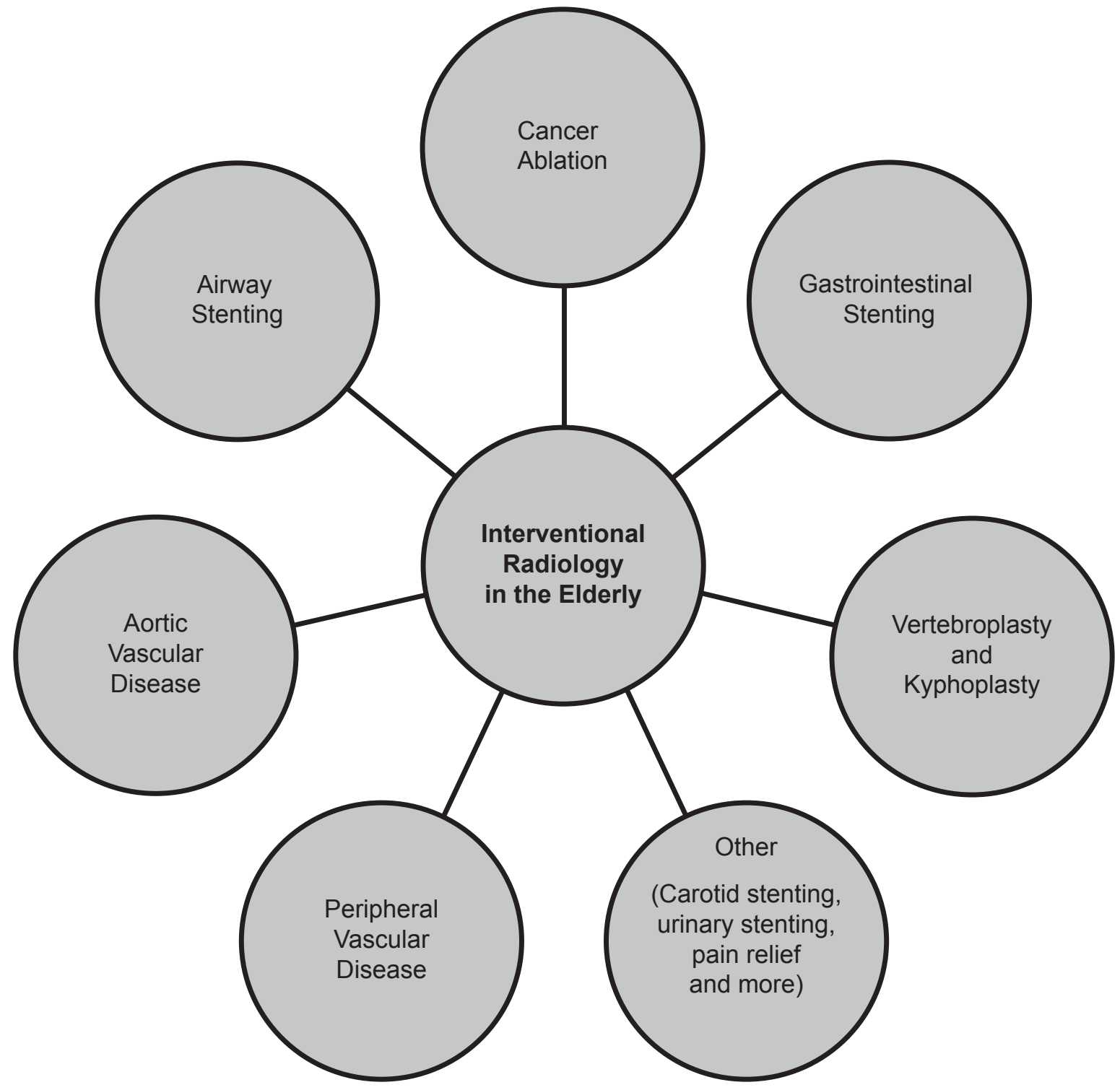

Figure I Diagram of interventional radiology procedures.

procedures in obstructive nephropathy, carotid stenting of atherosclerotic extracranial carotid disease, interventional therapy of deep venous thrombosis and pulmonary embolism and various interventions for chronic pain relief. Amassed evidence is generally limited to uncontrolled observational series and prospective studies, because the associated comorbidities and low performance status of the geriatric population usually prohibits properly conducted head-to-head randomized controlled trials.

All procedures described in the present review paper are performed by appropriately trained interventional specialists, who are capable to carry out a successful intervention and take on responsibility and management of any procedure-related complications within a wide multidisciplinary team of clinical specialties that may include interventional radiologists, interventional cardiologists, vascular surgeons, thoracic surgeons, general surgeons, orthopedic surgeons and oncologists.

\section{Cancer ablative therapies}

Cancer remains the second leading cause of death with a well-recognized increasing burden of cancer in the elderly population. The risk of cancer development increases exponentially with age above 60 years and almost two thirds of all new cancers afflict people older than 65 years. ${ }^{7,8}$ Solid organ oncological interventions have a rapidly expanding role within interventional radiology. A wide range of radiological locoregional ablative techniques is available, which induce 
tumorous cell death primarily through coagulative necrosis or ischemia. They may be broadly categorized into thermal ablation, mainly encompassing radiofrequency ablation, microwave ablation and cryoablation, chemical ablation by alcohol or acetic acid and transcatheter embolization with or without additional targeted chemotherapy.

At the moment, radiofrequency ablation (RFA), which was first applied in the early 1990s for the treatment of hepatic tumors, ${ }^{9}$ is by far the most widely adopted and commonly employed technique for percutaneous thermocoagulation of solid organ malignancies. ${ }^{1,2}$ RFA applicators with straight or expandable electrodes are introduced percutaneously under computed tomographic or ultrasonographic guidance into the center of the target tumor. Then, a high-frequency alternating current (460-500 kHz) is delivered through the lesion, which causes agitation of the tissue ionic molecules, which in turn produces frictional heat. Local tissue temperatures approach $100^{\circ} \mathrm{C}$ resulting in coagulative necrosis of the tumor. Ablation treatment must include a $0.5-1 \mathrm{~cm}$ margin of healthy tissue around the target lesion in order to obliterate any microscopic satellite foci and avoid early local recurrence. ${ }^{2,10}$ The efficacy of RFA may be limited by adjacent high-flow vascular structures, which act as a cooling circuitry (widely known as the heat-sink phenomenon) and increased tissue impedance in case of tissue boiling and/or charring. ${ }^{10}$ Microwave thermocoagulation is an emerging technology, which depends on the application of an electromagnetic wave (around $900 \mathrm{MHz}$ ) through an electrode-antenna. Electromagnetic microwaves travelling through tissue evoke agitation of ionic molecules and production of frictional heat, which results in tissue coagulative necrosis. Of note, microwave ablation technologies have certain inherent advantages over RFA, since they operate independent of any electrical current convection and are less influenced by tissue impedance variabilities and heat sink phenomena. Microwave tumor ablation is gradually gaining place as a more versatile and efficient method of tissue thermocoagulation, because it can achieve higher intratumorous temperatures and larger ablation zones more quickly than RFA. ${ }^{2,10,11}$

Primary hepatocellular carcinoma and metastatic liver disease (where local control can often improve life expectancy) have both been treated with RFA and a survival benefit has been demonstrated. ${ }^{12}$ A magnitude of prospective cohort studies in patients unfit for surgery for various reasons have provided the first evidence base for more widespread application of liver radiofrequency ablation. ${ }^{13,14}$ Referred patients most commonly have inoperable disease or are unfit for liver surgical resection. RFA is best suited for localized primary hepatic tumors (one lesion less than $5 \mathrm{~cm}$ or three lesions less than $3 \mathrm{~cm}$ each). ${ }^{10}$ In a single-center RFA study of primary hepatocellular carcinoma in 206 cirrhotic patients, considered ineligible for transplantation or surgical resection, survival rates at 1, 3 and 5 years were $97 \%, 67 \%$, and $41 \%$ on an intention-to-treat basis, respectively, after a median follow-up period of 2 years. ${ }^{15}$

Unlike surgery, RFA tumor ablation can be performed as a day case procedure under conscious sedation and has less morbidity and mortality. ${ }^{10}$ RFA may be repeated for new or recurrent disease and has a lower complication rate due to its minimally invasive nature. ${ }^{16}$ Reported mortality is $0.5 \%$ and associated complication rates range from $8 \%$ to $35 \%$, mostly encompassing minor cutaneous burns, abscess formation and self-limiting post-ablation syndrome. RFA also has an intrinsic electrocautery effect, which potentially minimizes bleeding complications. Benign post-ablation biliary strictures and tumor seeding along the electrode tract remain rare. ${ }^{2,10}$

In parallel, there are reports of a survival benefit in patients with hepatic colorectal metastases unfit for surgical metastasectomy and treated with RFA. ${ }^{12,17}$ Reported 5 -year survival rates compare very favorably with operable candidates who have undergone resection $(30 \%$ with RFA vs $39 \%$ with surgery). ${ }^{16}$ RFA also has the added benefit of preserving bigger volumes of functioning liver tissue and thereby allowing for repeat sessions in the future, even in cases of multiple dispersed liver metastases. ${ }^{10}$ However, despite widespread adoption and incorporation of liver RFA into modern multidisciplinary management of liver cancer, more rigorous controlled trials are warranted to further elucidate its role in prolonging patient survival. ${ }^{13,14}$

There is also a growing body of evidence regarding thermocoagulation of renal cell carcinoma. ${ }^{10,11,18}$ RFA of renal cell carcinoma is an appealing curative treatment for small and exophytic tumors or when patients are too old and frail to undergo partial or complete nephrectomy (Figure 2). ${ }^{11,19}$ However, large or central hilar tumors are more difficult to ablate completely due to heat-sink effect from high blood flow at the renal hilum and increased risk of complications from the collecting system; mainly benign post-ablation strictures and urinoma formation. ${ }^{1,11}$

Lung cancer remains the leading cause of cancer death in men and women and is biologically characterized by an extended time period between exposure to carcinogenic chemicals and tumor development. ${ }^{20}$ Unfortunately, elderly people, in particular octogenarians, are less likely to be 


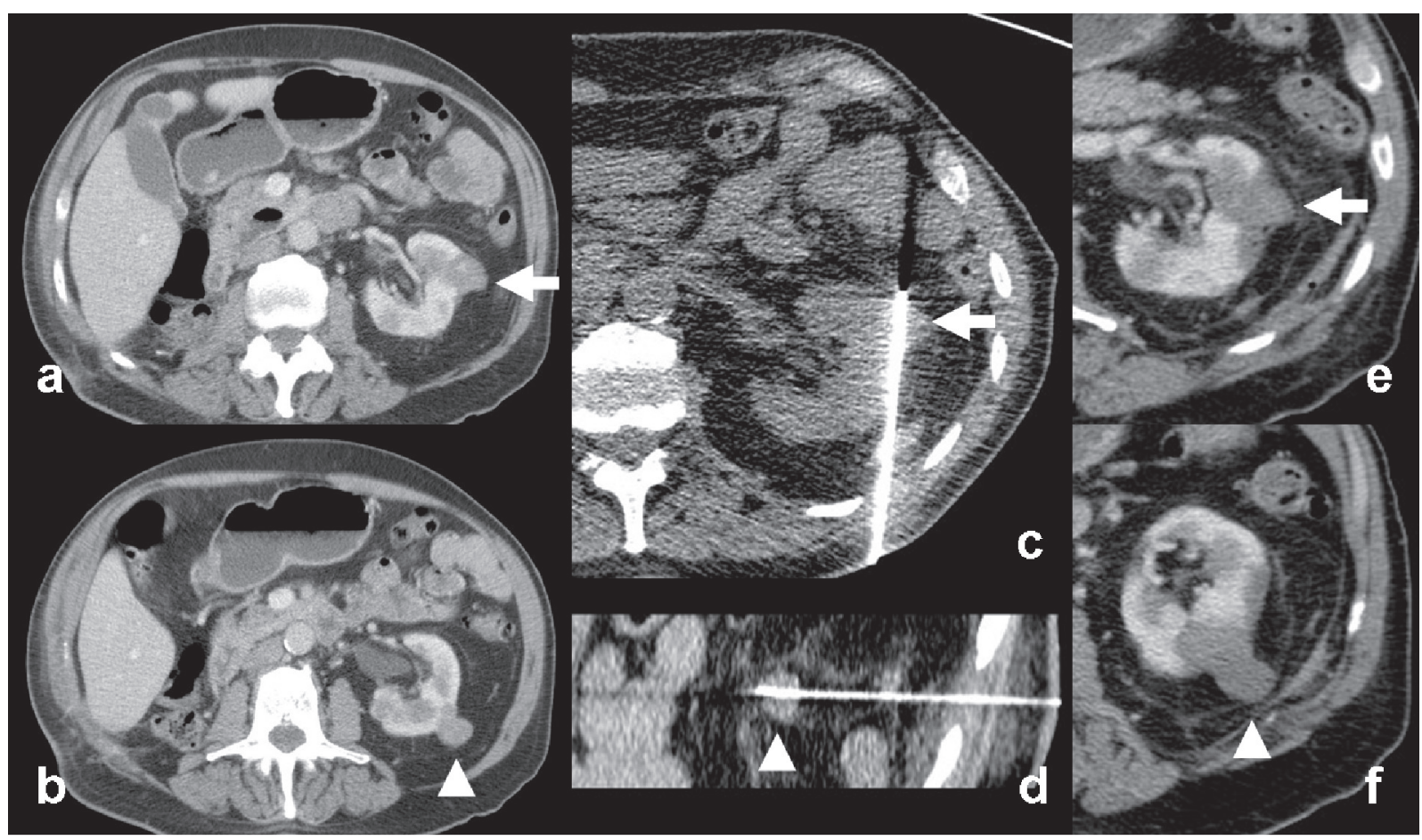

Figure 2 Example of radiofrequency ablation of renal cell carcinoma. (a-b) An 86-year-old male patient with solitary left kidney (history of unilateral nephrectomy for renal cell carcinoma (RCC) 5 years ago) presented with 2 small exophytic renal tumors (white arrow and arrowhead). Percutaneous biopsy confirmed the histological diagnosis of RCC. (c-d) Percutaneous RFA of the two lesions under CT guidance (Cool-tip Valleylab RFA system, Tyco Healthcare, Hampshire, United Kingdom). Note the insertion of the RFA electrodes into the tumors (e-f) follow-up imaging show absence of contrast enhancement, congruent with complete tumor necrosis (white arrow and arrowhead).

offered surgical resection as a first-line curative treatment option owing to either coexisting comorbid conditions or advanced disease at the time of diagnosis. ${ }^{20}$ Poor heat conductivity of the surrounding air makes lung lesions particularly suitable to RFA ablation, as heat remains localized into the lesion. Elderly surgically unfit patients with early (stage 1) nonsmall cell lung cancer (NSCLC) and those with limited metastases can be typically offered the treatment. ${ }^{10}$ However, published evidence of radiofrequency ablation of lung tumors is still limited to observational studies and case series that have demonstrated favorable safety profile and low recurrence rates around $11 \% .{ }^{21} \mathrm{~A}$ systematic literature review of lung RFA showed that the median progression-free interval ranged from 15 to 27 months (median $=21$ months), and 1 -, 2 - and 3-year survival rates were $63 \%-85 \%, 55 \%-65 \%$, and $15 \%-46 \%$, respectively. ${ }^{21}$ In view of growing evidence regarding lung stereotactic radiation therapy that also shows promising local control rates, randomized controlled trials between the two types of treatment are warranted. ${ }^{22}$

Finally, application of RFA is particularly appealling for pain management of intractable metastatic bone disease. Up to $85 \%$ of patients presenting with breast, prostate and lung cancer have evidence of bone metastases at the time of death. ${ }^{23}$ Relief of pain from these deposits is an important aspect of palliative care. Radiation therapy can take weeks to take effect and fails to relieve pain in up to $30 \%$ of patients. ${ }^{24}$ There are several ablative techniques that have been used to treat bone metastases. Percutaneous ethanol injection causes coagulative necrosis through cellular dehydration. Severe pain from bone metastases may be treated by this method when conventional therapies such as opiate analgesia, chemotherapy and radiotherapy are ineffective, too slow acting or cause unacceptable side effects. ${ }^{25,26} \mathrm{RFA}$ is particularly suited to bone metastases that are unsuitable for alcohol ablation due to their proximity to nerves or when intra-articular leak of alcohol may occur. ${ }^{26} \mathrm{~A}$ multicenter trial of patients with painful bone metastases in whom other therapies including radiotherapy and chemotherapy had failed found sustained pain relief in $95 \%$ of patients..$^{27}$ Of interest, cryoablation is an alternative technique that freezes lesions to form an "ice-ball". Similar results to RFA have been achieved in providing pain relief for bone metastases. ${ }^{28}$ Although the procedure takes more time than RFA, the extent of the cryoablation zone is more easily appreciated and monitored with conventional computed tomography, which allows the lesion to be more extensively treated without posing risks to surrounding structures. ${ }^{24}$ Complications of bone deposit ablation include damage to surrounding structures such as 
nerve roots, bowel and bladder symptoms, formation of tumor-cutaneous fistulae, and pathological fractures. ${ }^{24,27}$ If a pathological fracture is anticipated, then cementoplasty (deposition of cement inside the ablation area based on the same principles of vertebroplasty (see dedicated section of the present overview below) may be performed to stabilize the treated bone, usually the vertebrae or the acetabulum. ${ }^{10,25}$

A further field of tumor ablative therapy includes arterial intervention. Selective endovascular catheterization of tumors is performed with the aim of embolization or delivering regional chemotherapy. Embolization may be used to reduce tumor size or blood loss prior to surgery or to palliate patents that are poor surgical candidates and require symptom relief. Any hypervascular tumor such as metastastic renal cell or thyroid carcinoma may benefit from embolization. Further analysis about the application of transarterial embolization techniques in cancer treatment is described elsewhere. ${ }^{2,29}$

\section{Palliative stenting of the gastrointestinal tract}

Aging remains a significant risk factor for cancer of the alimentary tract. The majority of esophageal, gastric, pancreatic and colorectal cancers are detected in elderly people; ie, older than 65 years. ${ }^{30}$ Moreover, commonly applied treatments of surgery, chemotherapy, radiation or combinations thereof can be associated with significant complications and morbidity or may be intolerable in the setting of advanced age and underlying comorbidities. Unfortunately, more than 50\% of esophageal and gastroduodenal cancer cases present with advanced disease and are not eligible for curative resection at the time of diagnosis. ${ }^{31,32}$ Minimally invasive radiological stent placement is a palliative treatment option that is routinely offered nowadays to patients with unresectable tumorous obstructive disease of the gastrointestinal tract.

Stenting is actually an established form of treatment in a wide range of pathological conditions. Tracheobronchial stenting provides symptomatic relief from endoluminal disease or external tumor compression. Biliary and ureteric stenting are either used to palliate malignant obstruction or as a temporary measure in stone disease. Gastrointestinal (GI) stenting is used in upper GI; oesophageal and gastroduodenal; and lower GI; colonic; malignant obstructive pathology.

Stents are designed to maintain patency, avoid re-obstruction and minimize the risk of migration. Stents may be balloonexpandable or self-expanding and are manufactured from stainless steel or other alloys. Nitinol (an alloy of nickel and titanium) self-expanding stents assume a predictable shape at body temperature when deployed and are generally preferred in the gastrointestinal tract. They provide radial force, which pushes against an obstructive lesion. Stents may be covered (usually with silicone and polyethylene covers) or uncovered, consisting of a nitinol mesh only. ${ }^{31-34}$ Covered stents usually resist tumor ingrowth and therefore prevent re-obstruction but are less stable and more rigid, requiring larger delivery systems and are more prone to migration. Uncovered stents are more flexible and easier to deliver and deploy but are subject to tumor ingrowth. Many stents are also designed to prevent migration by having flared ends. For the purposes of this review the following is a discussion of the principles, advantages and complications of esophageal, gastroduodenal and colonic stent insertion. This technique exemplifies the benefits stenting can have over more traditional forms of treatment, particularly in an elderly population.

Palliative therapy in case of advanced esophageal carcinoma aims to maintain oral food intake and relieve pain, while avoiding aspiration, reflux and regurgitation. ${ }^{31}$ Over the last decade, self-expanding metal stents have become the endoluminal treatment of choice for rapid relief of dysphagia in patients with advanced stage esophageal carcinoma. ${ }^{33,34}$ Indications for esophageal stenting generally include tumorous esophageal obstruction or extrinsic compression, malignant esophageal perforation and tracheoesophageal fistula, as well as refractory benign strictures. ${ }^{31,34}$ Esophageal stent insertion is usually performed after completion of chemotherapy and radiotherapy to avoid tumor shrinkage, which predisposes to stent migration. Esophageal stents are typically inserted transorally under conscious sedation. ${ }^{31}$ The technical success rate of radiological esophageal stent insertion is almost $100 \%$ with impressive and rapid relief of dysphagia. ${ }^{34}$

Early procedure-related complications of esophageal stenting include lung aspiration, hemorrhage and esophageal perforation, which may occur in $10 \%-20 \%$ of the cases. ${ }^{31,35}$ Hemorrhage is usually self-limited, perforation is uncommon and procedure-related mortality is very low, ranging from $0 \%$ to $1.4 \% .^{35,36}$ Late recurrent dysphagia as a result of tumor overgrowth at the stent edges or ingrowth through the mesh of uncovered stents may be as high as $60 \%$, and is usually treated with repeat co-axial placement of another stent. ${ }^{34,35}$ Other delayed complications are mostly device-related and may include stent migration, stent torsion, stent fracture or tracheoesophageal fistulation. ${ }^{35,37}$

Of note, percutaneous gastrostomy or gastrojejunostomy may be particularly helpful in patients with inoperable and unstentable carcinoma of the upper gastrointestinal tract that require prolonged enteral feeding. Disruption 
of normal swallowing in the elderly because of stroke or degenerative neurological conditions is another indication of the procedure. ${ }^{38,39}$ With a combination of ultrasound and X-ray guided gastropexy various types of gastrostomy or gastrojejunostomy tubes may be inserted. The latter are preferred in cases of gastroesophageal reflux or tumorous gastric outlet obstruction. Operators have to be extremely careful of liver laceration, perforation of the transverse colon and tube misplacement. ${ }^{39}$

Stenting can also be applied to alleviate malignant gastroduodenal and colonic obstruction. Patients with malignant gastric outlet or duodenal obstruction exhibit gastric distension, intractable vomiting and complete food intolerance leading to severely impaired quality of life. ${ }^{32}$ They typically suffer from dehydration and electrolyte imbalances and are at increased risk of aspiration pneumonia. ${ }^{40,41}$ Large-diameter, self-expanding enteral stents can be inserted to relieve gastroduodenal obstruction and re-establish oral intake in patients with poor general condition. Nowadays, gastroduodenal self-expanding stenting has become the treatment of choice for rapid palliation of gastric outlet and duodenal obstruction in pre-terminal patients with advanced upper gastrointestinal malignant disease (Figure 3). ${ }^{32}$

Indications for gastroduodenal stenting include inoperable extrinsic or intrinsic malignant strictures due to stomach, duodenal, pancreatic and cholangiocarcinoma, lymphadenopathy and post-surgery anastomotic recurrent disease. ${ }^{32}$ Gastrointestinal perforation with symptoms of peritonitis, peritoneal carcinomatosis, distal small bowel obstruction and uncorrectable coagulopathy are typical contra-indications for the procedure. The procedure is performed transorally under conscious sedation and fluoroscopic guidance..$^{32}$ Although large-diameter uncovered stents are routinely deployed, covered stents may be helpful to exclude malignant fistulae

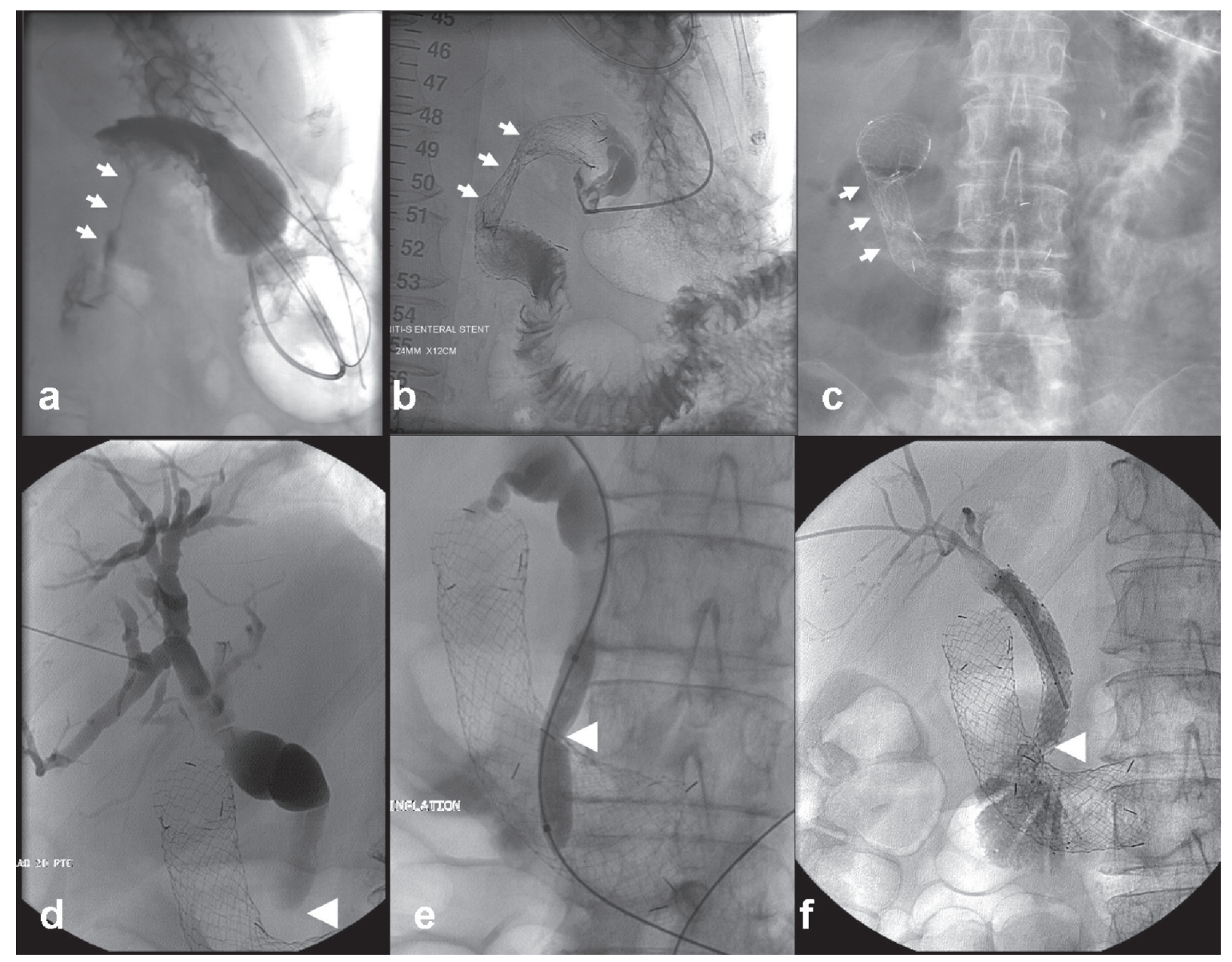

Figure 3 Example of combined gastroduodenal and biliary stenting. (a) A 76-year-old female patient with inoperable duodenal adenocarcinoma encroaching the lumen of the duodenum (white arrows). (b) Transoral insertion of an I8-mm self-expanding stent (Niti-S duodenal stent, Pyramed, Esher, United Kingdom; TaeWoong Medical, Seoul, Korea) to relieve gastric outlet obstruction (white arrows). (c) Note the full expansion of the stent the following day (white arrows). (d) The next week the patient developed obstructive jaundice (likely from the stent compressing the tumor against the ampulla). (e-f) Percutaneous transhepatic cholangiography demonstrates marked dilatation of the biliary tree, which was treated with biliary stent insertion (Zilver, Cook Medical, Bloomington, United States) after ballooning through the duodenal stent mesh. Note the stent placed in the common bile duct and extending across the mesh of the duodenal stent (white arrowhead). 
to adjacent organs. The technical success of gastroduodenal stent insertion approaches $100 \%$, but clinical success to relieve symptoms and restore oral feeding is nearer $90 \%$ because of either progressive distal disease or lack of functional stomach peristalsis (chronically obstructed stomach or tumor infiltration of coeliac axis neural plexus). ${ }^{42}$ The procedure is generally safe and well tolerated with a reported $0 \%$ mortality and less than $1 \%$ major complications including perforation and hemorrhage. Of note, early intraprocedural perforation or late perforation by erosion of the stent ends through the intestinal wall may be a surgical emergency. ${ }^{42}$ Similarly to esophageal stenting, stent migration occurs less frequently with uncovered stents, whereas reobstruction because of tumor ingrowth is treated with repeat co-axial stenting. ${ }^{32,41}$

Large bowel obstruction due to malignant colorectal cancer is also a common, major surgical emergency. Presenting patients are typically elderly with multiple co-morbidites including metabolic and electrolyte disturbances, intestinal ischaemia and sepsis. Emergency surgery has mortality up to $20 \%{ }^{43}$ and Hartmanns procedures (resection and terminal colostomy) are suboptimal in elderly patients due to stoma care issues and many cases not being reversed.

Colonic stenting has a number of advantages related to emergency surgery being avoided in favor of elective surgery. This allows optimization of the patient, preoperative radiological staging, multidisciplinary team discussion, neoadjuvant therapy and primary anastomosis to avoid a two-stage procedure. A recent analysis paper comparing colonic stenting as a bridge to surgery versus surgery alone for emergent left colonic obstruction found it to be more effective with reduced peri-procedural mortality and less likely to require a permanent colostomy. ${ }^{44}$ The benefits were greatest among those who were at highest risk of surgery. Stenting can also be used as a palliative measure in those patients that are unsuitable for surgery.

Colonic stenting requires minimal patient preparation. Most patients have a computed tomography (CT) scan and water-soluble enema to confirm the diagnosis, exclude perforation and assess the position and degree of stenosis. The procedure is carried out with the patient sedated in a left lateral position. Most left sided colonic lesions can be crossed with fluoroscopic guidance using a combination of wires and catheters. Lesions more proximal than the splenic flexure may require endoscopic assistance. The only absolute contraindications are perforation, distal rectal lesions (where a healthy landing zone above the anal sphincter mechanism cannot be obtained) and obstruction involving multiple sites, (most commonly found with pelvic cancers, serosal metastases and lymphadenopathy). ${ }^{45}$

A pooled safety and efficacy analysis of prospective colonic stenting studies encompassing around 1,200 patients demonstrated median technical and clinical success rates of $94 \%$ and $91 \%$, respectively, with a stent-related mortality of $0.58 \% .{ }^{43}$ The clinical success of colonic stenting as a bridge to surgery was $71.7 \% .{ }^{43}$ Stenting is also more cost effective than traditional surgical options and palliative stenting has been shown to improve quality of life when compared with surgery. ${ }^{46}$ Shorter hospital stay and a cost reduction between approximately $20 \%-30 \%$ have also been observed. ${ }^{47}$ Colonic stenting is a relatively low-risk procedure with a mortality rate around $1 \%$. When the stent is placed very near the anorectal canal tenesmus and transient incontinence can occur. Self-limiting haemorrhage is a minor complication, which is most likely related to the disease process itself.

Of note, performing physicians must be particularly vigilant of colonic perforation, which has an overall incidence of $4 \%$ and carries a $10 \%$ mortality rate. ${ }^{48,49}$ The risk increases with balloon dilatation of the diseased segment before stent deployment and excessive manipulation of guidewires (especially in the presence of diverticular disease). ${ }^{45}$ It can also occur as a late complication due to stent erosion, radiotherapy or chemotherapy. ${ }^{50}$ Migration of colonic stents has been reported in $12 \%$ of cases. ${ }^{43}$ Most stents migrate distally and pass through the anus, while symptomatic stents may be removed endoscopically. Finally, stent re-obstruction, which occurs in approximately $10 \%$ of the cases because of tumor ingrowth or overgrowth, can be treated by co-axial deployment of a second. ${ }^{48,51}$

\section{Tracheobronchial stenting}

Airway stenting may be applied to alleviate malignant or benign strictures of the tracheobronchial tree with impending asphyxia and death (Figure 4). The procedure may be either palliative for inoperable primary or secondary lung or neck neoplasms encroaching or compressing the airway, or temporary for benign disease like inflammatory and anastomotic strictures, post-intubation stenosis and tracheobronchomalacia. ${ }^{52-55}$ Patients with advanced malignant obstructions may present with hemoptysis and chest pain, severe dyspnea and stridor, being on the verge of suffocation. Given the limited life expectancy and poor performance status of these patients, urgent airway stenting is a sufficient and effective palliative therapy ${ }^{53,54}$ The procedure generally involves mutidisciplinary evaluation and execution from a team of oncologists, surgeons and interventional radiologists. A combination of rigid or 


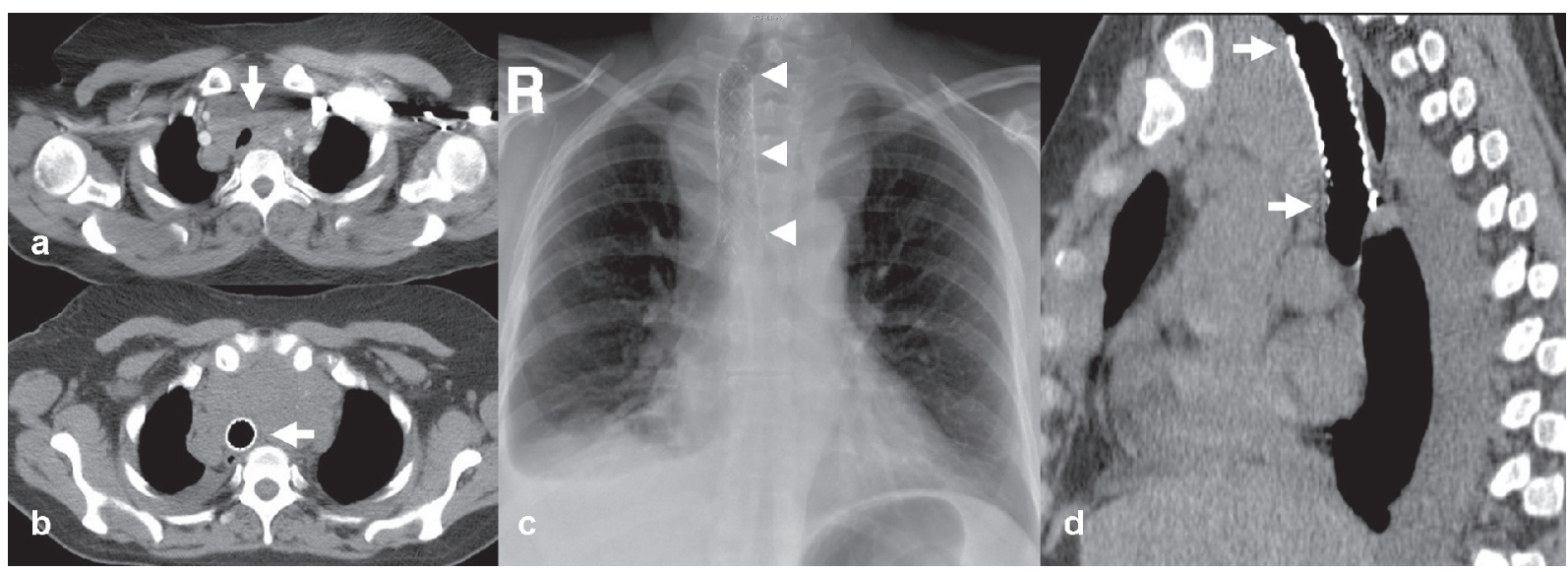

Figure 4 Example of palliative tracheal stenting. (a) A 67-year-old female with metastatic breast cancer and extensive mediastinal lymphadenopathy severely compressing and displacing the trachea (white arrow). (b) axial CT image, (c) plain chest X-ray, and (d) sagittal reformatted CT image show a self-expanding uncovered stent (Pyramed, Esher, United Kingdom) deployed in the trachea to restore luminal patency and avoid suffocation.

flexible endoscopy and plain fluoroscopy under general anesthesia is the safest approach for accurate stent deployment with minimal complications..$^{52,53}$ Dedicated airway stents are typically self-expanding and may be uncovered or covered; composed either from plastic or metal alloys. Technical success rates are very high $(98 \%-100 \%)$, but clinical success rates are somewhat lower, at the level of $88 \%-100 \%$ for benign conditions and $82 \%-92 \%$ for malignant disease. ${ }^{54}$ Similar to applications in other hollow organs, uncovered stents mostly suffer from neoplastic tissue ingrowth and covered ones from migration. Stent-related complications are more frequently encountered in the long-term treament of patients with benign airway stenoses and include decreased mucociliary clearance and sputum impaction, development of granulation tissue at the stent edges, stent migration and fracture. ${ }^{54,55}$ Further studies are necessary to identify specific patient groups who may have the most benefit from stenting, as well as which type of stent is more suitable for the airways. ${ }^{56}$

\section{Endografts for aortic vascular disease}

Abdominal aortic aneurysm (AAA) is an age-related disease. ${ }^{57}$ AAA patients over 80 years old are often denied open surgical repair because of underlying comorbidities. ${ }^{57,58}$ Advanced age on its own has also been identified as an independent strong predictor of increased peri-operative death and post-operative adverse events following surgery of the thoracic or abdominal aorta. ${ }^{57,59}$ Endovascular aneurysm repair (EVAR) is now commonly used to treat elderly patients with amenable anatomy (Figure 5). Parodi and colleagues reported the first successful clinical application of an appropriately engineered endograft for AAA exclusion in $1991 .{ }^{60}$ Ever since, the introduction of new devices with lower profile and higher flexibility and conformability allow continuous expansion of anatomical inclusion criteria and today more elderly patients may qualify for the procedure. New generation endograft devices are smaller, more durable and far easier to advance through tortuous iliac arteries and deploy across angulated AAA necks. ${ }^{1,58}$ Most importantly, evidence from of large multicenter randomized trials has demonstrated decreased peri-procedural mortality and morbidity of EVAR compared to open surgical repair series, although both procedure- and aneurysm-related mortality remain notably higher in older than in younger patients..$^{57,61}$ Moreover, EVAR is related to significantly less hospital stay and earlier patient ambulation and return to preoperative levels of activity. ${ }^{1}$

According to a meta-analysis, which included 1534 patients treated surgically and 1045 patients treated endovascularly for AAA, pooled mortality and morbidity was $7.5 \%$ and $31 \%$ after open repair compared to $4.6 \%$ and $11.5 \%$ following EVAR. ${ }^{57}$ Nonetheless, long-term survival seems to be comparable for both techniques and device-related re-interventions are more common with EVAR. ${ }^{1,57}$ Thus, the actual benefit of EVAR in terms of life years gained for elderly patients, especially for those over 80 -years-old, remains questionable to date..$^{58}$ Overall, however, the current status of EVAR continues to be exceptionally robust and promising. Recently, fenestrated and branched customized endografts have been successfully applied for the endovascular exclusion of complex suprarenal and juxtarenal thoracoabdominal aortic aneurysms in surgically unfit patients. ${ }^{62}$

In parallel, there has been tremendous progress in endovascular minimally invasive treatment of thoracic aortic disease.$^{58}$ Following the early clinical enthusiasm with 


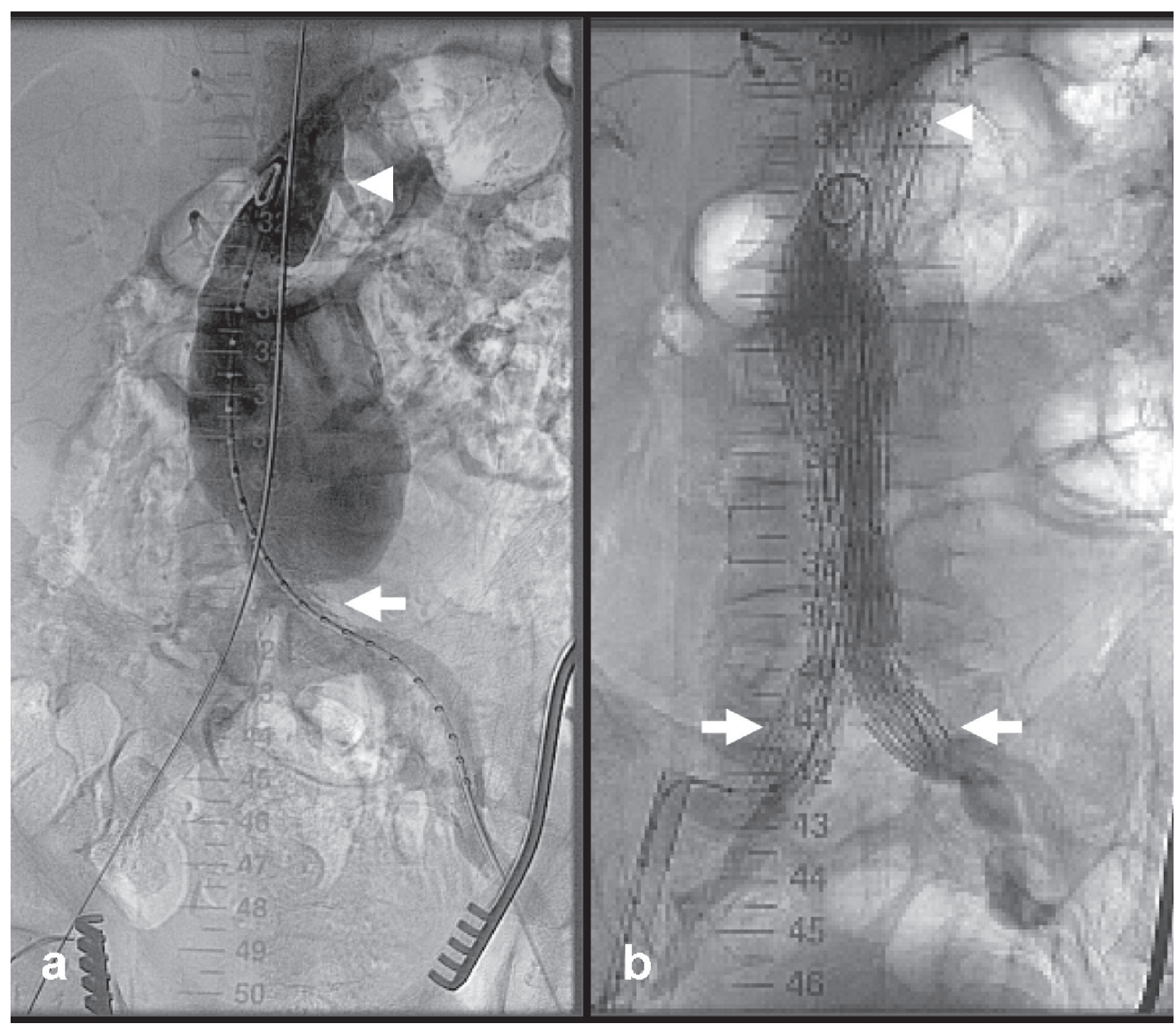

Figure 5 Example of endograft insertion for abdominal aortic aneurysm. (a) An 83-year-old male with an incidental finding of a 6.7-cm infrarenal abdominal aortic aneurysm extending to the aortoiliac bifurcation (white arrow). (b) Aneurysm was successfully excluded with transfemoral insertion of a bifurcated endograft device (Zenith AAA Endovascular Graft, Cook Medical, Bloomington, United States). Note the suprarenal fixation of the device (white arrowhead) and the distal landing in the common iliac arteries (white arrows) to minimize risk of endoleak.

endograft exclusion of AAAs, Dake and colleagues pioneered the same endovascular technique in the management of descending thoracic aortic aneurysms in $1994 .{ }^{63}$ Ever since, a rapidly growing number of applications have been reported for a wide spectrum of thoracic aortic syndromes. These include and are not limited to acute and chronic aortic dissection, penetrating atherosclerotic ulcer, traumatic aortic transection, mycotic aneurysm, and rupture. ${ }^{64,65}$ Although high-level clinical evidence from randomized controlled trials is still missing, elderly and frail patients are probably the ones to enjoy the most clinical benefit in this new era of endovascular treatment of thoracic aortic diseases. ${ }^{66}$

\section{Infrapopliteal angioplasty for critical limb ischemia}

Critical limb ischemia (CLI) refers to limb-threatening peripheral atherosclerosis, and is typically characterized by multilevel, infrainguinal and infrapopliteal arterial occlusive disease ${ }^{67-69} \mathrm{CLI}$ has an estimated incidence of 500-1000 per million per year and primarily afflicts elderly patients with diabetes mellitus. ${ }^{70}$ Almost 170 million people suffer from diabetes worldwide with a projection to double by $2030 .{ }^{71}$ Diabetic foot ulcers affect approximately $15 \%$ of all diabetics and are identified in $84 \%$ of diabetes-related lower extremities' amputations owing usually to a combination of neuropathy and CLI symptoms. ${ }^{71,72}$ Deficiencies in more than 100 physiologic factors implicated in the cascades of angiogenesis, tissue regeneration and normal wound healing have been identified in diabetic ischemic feet. ${ }^{71}$ The presence of diabetes mellitus accentuates the risk of CLI by four times and diabetic patients with CLI are ten times more prone to amputation than normoglycemic patients. ${ }^{73}$ If CLI is left untreated, it has a dispiriting natural course with an estimated $25 \%$ major amputation and $25 \%$ cardiovascular 
mortality rate at 1 year. ${ }^{70}$ In the interest of preventing limb loss or minimizing the extent of pre-planned amputation, CLI patients must undergo urgent percutaneous or surgical recanalization of the peripheral arteries.

Although bypass surgery remains the cornerstone of CLI treatment, the majority of the patients are rendered ineligible because of diffuse infrapopliteal arterial occlusions, absence of suitable vein grafts and multiple underlying comorbidities. ${ }^{72,73}$ On the other hand, modern developments in endovascular instruments and the growing skills of vascular interventional radiologists have driven a paradigm shift in CLI treatment towards percutaneous transfemoral infrapopliteal angioplasty and stenting. ${ }^{69,73}$ Compared to surgery, angioplasty is a minimally invasive procedure with a clear benefit of reduced complications and peri-procedural adverse events, especially in the frail patient cohort of elderly octogenarians ${ }^{69,74}$ In addition, it may be repeated as necessary and more than one occluded vessels to the foot may be recanalized.

Amassed evidence regarding the overall effectiveness and safety of infrapopliteal angioplasty supports its application as first-line treatment option for infrapopliteal obstructive arterial disease for CLI treatment. ${ }^{67,69,72}$ The primary goal of infrapopliteal angioplasty is to restore at least one straight line of blood vessel to the distal foot (Figure 6). The secondary objective is to preserve the patency of the treated lesion for as long as possible to avoid recurrence of CLI. In the majority of the cases infrapopliteal angioplasty is combined with more proximal endovascular procedures. Occasionally, it may be applied in tight distal anastomotic lesions of bypass grafts to avoid early graft failure and thrombosis. Reported complications rates range from $3 \%$ to $11 \%$ and include puncture site hematomas, vessel perforation, dissection and distal embolism or thrombosis, which may be successfully

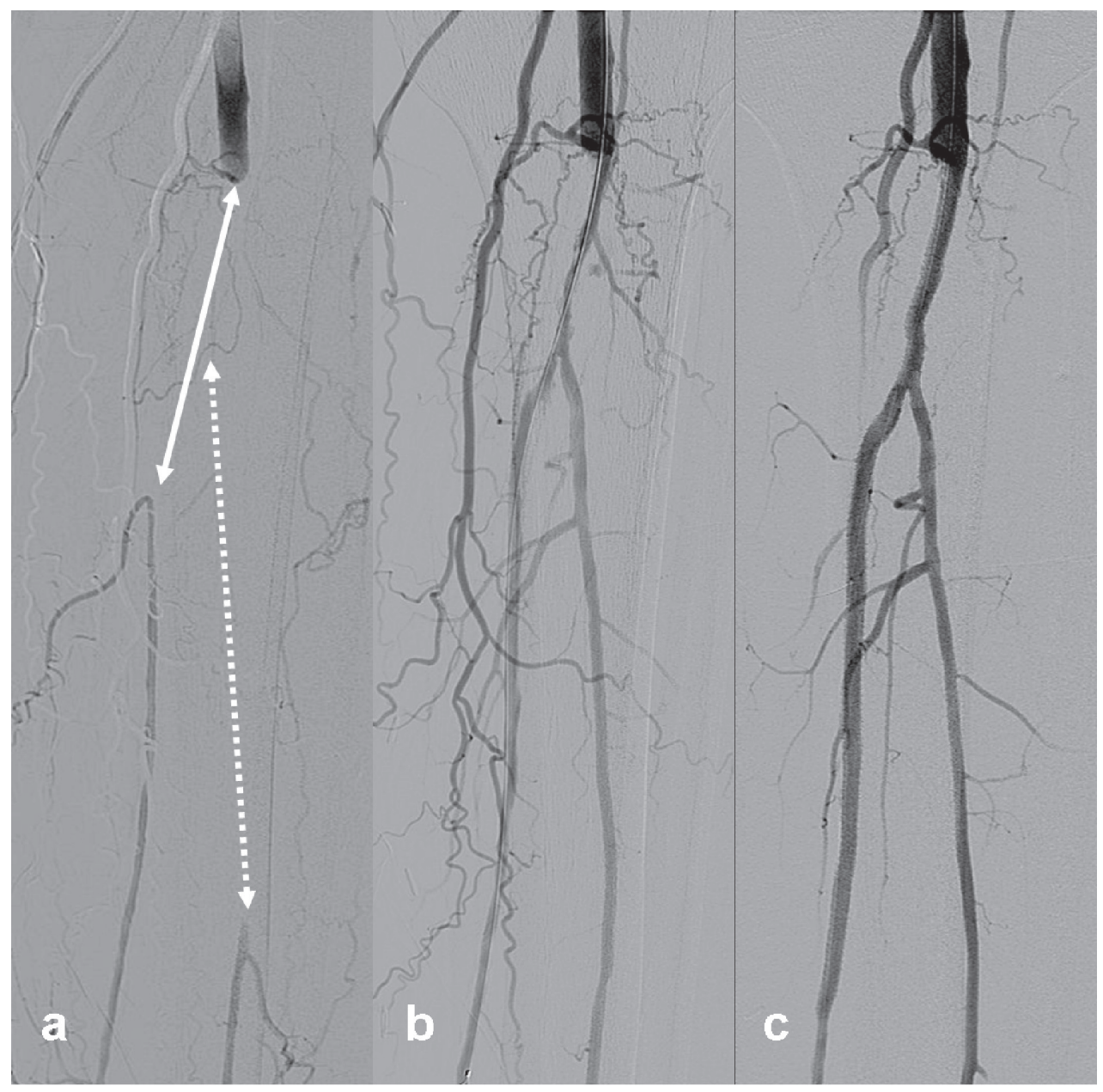

Figure 6 Example of infrapopliteal angioplasty and stenting for critical ischemia. (a) Angiogram of infrapopliteal arteries of a 79-year-old diabetic male with left leg critical limb ischemia (nonhealing heel ulcer). Note the long occlusions of the tibioperoneal-posterior tibial (white straight line) and peroneal (white dotted line) arteries. (b) Angiograms after initial balloon angoplasty and (c) after additional drug-eluting stenting (CYPHER Drug-eluting stent, Cordis, Waterloo, Belgium) show successful recanalization of both arteries to the distal foot. The patient experienced immediate relief of rest pain and the ulcer healed gradually within three months. 
managed by endovascular means. The 30-day peri-procedural mortality rate is less than $1.7 \%{ }^{69}$

A random effects meta-regression analysis of 18 studies published between 1984 and 1997 and including 1280 patients treated with infrapopliteal balloon angioplasty reported overall limb salvage rates of $79 \%$ at 1 year and $74 \%$ after 2 years. ${ }^{75}$ A more recent meta-analysis of 30 studies published between 1990 and 2006 reported 3-year limb salvage and patient survival probabilities of $82.4 \%$ and $68.4 \%$, respectively. ${ }^{76}$ In comparison the 5-year limb salvage rates using autogenous veins for infrapopliteal bypasses range from $73 \%$ to $81 \%{ }^{77}$ Unfortunately, short-term angiographic vascular restenosis is high, and infrapopliteal occlusion reportedly recurs in as many as $50 \%$ of the cases by 1 year resulting in a high frequency of repeat procedures. ${ }^{72,73,78}$ Although infrapopliteal application of bare metal stents is safe and feasible, it is associated with significant neointimal hyperplasia and early restenosis. ${ }^{67-69,79}$ Motivated by the success of drug-eluting stents in the coronary arteries, researchers have applied them in the infrapopliteal arteries to forestall vascular restenosis and prolong amputation- and reintervention-free survival of CLI patients. Recently published data about application of drug-eluting stents (DES) show favorable clinical results at 6 and 12 months with significantly higher angiographic patency and less clinically driven re-interventions when compared to bare metal stents. ${ }^{72,73,78,80,81}$

\section{Vertebroplasty for osteoporotic vertebral fractures}

Osteoporosis is a significant cause of morbidity and mortality in an aging population. Osteoporotic vertebral fractures are a cause of severe back pain and immobility in elderly patients. Consequences include loss of independence and increased risk of deep venous thrombotic and respiratory complications. Fractures can occur after minor trauma and may involve acute collapse or micro fractures without a compressive component. It is believed that pain is related to compressive loads causing movement of fracture fragments. This results in inflammatory changes and irritation of pain receptors. ${ }^{82}$ Pathological fractures secondary to vertebral body metastases and multiple myeloma are also important causes for severe back pain in elderly patients. Rapidly relieving pain to restore function and quality of life is an important goal of palliative therapy. These patients are particularly challenging. They often fail traditional medical therapy, are susceptible to the adverse effects of opiates, require more rapid relief than chemotherapy and radiotherapy can offer (and which can also be poorly tolerated) and are frequently surgically unfit. The role of both vertebroplasty and kyphoplasty lies in the management of those in whom medical management including opiate analgesia, bed rest and bracing have proved unsatisfactory or inadequate.

Vertebroplasty is a minimally invasive technique, which can be performed under conscious sedation as a day case procedure. It is used to treat pain related to vertebral body fractures or malignant infiltration. In patients with neurological symptoms it may also be used as an adjunct to surgery to provide vertebral stabilization prior to spinal decompression. ${ }^{83}$ Fluoroscopy (in some centres used in conjunction with computed tomography) is used to guide a needle through the posterior aspect of the vertebral body, using most commonly a transpedicular approach. Cement is injected under careful fluoroscopic guidance and uni- or bipedicular injections can be applied depending on operator preference, positioning of the needles and success of cement injection (Figure 7). Most operators will inject up to three levels at a single sitting. During the procedure bone biopsies may also be taken to confirm the suspected diagnoses.

Kyphoplasty is an alternative technique, which is similar to vertebroplasty but includes the additional step of introducing a high-pressure balloon into the vertebral body to form a cavity into which cement is injected. This technique produces a small but measurable restoration of the body height of the collapsed vertebrae. ${ }^{84}$ It also reduces the risk of cement leakage seen with vertebroplasty due to the formation of a cavity allowing low-pressure cement injection. ${ }^{82}$ Several large scale nonrandomized controlled trials and observational studies of vertebroplasty and/or kyphoplasty against best medical therapy have demonstrated their relative safety and superior effectiveness in treating painful osteoporotic vertebral fractures..$^{85,86}$

As with any interventional procedure patients should be assessed clinically to confirm their suitability. The vertebral fracture should be confirmed as the likeliest cause for the patients' pain and other causes such as degenerative changes and radiculopathy should be considered and excluded. Diffuse pain is unlikely to settle with vertebroplasty or kyphoplasty and symptoms should also correlate with the radiological findings. Patients may initially be diagnosed on plain film findings, however magnetic resonance imaging (MRI) is also normally undertaken to confirm edema within the fracture site (a good indicator that vertebroplasty will be effective) and assess for spinal cord involvement. CT and technetium 99m-pertechnetate bone scintigraphy have also been used. ${ }^{87}$ Contraindications include fractures which are asymptomatic or improving on medical therapy, as a prophylactic measure 


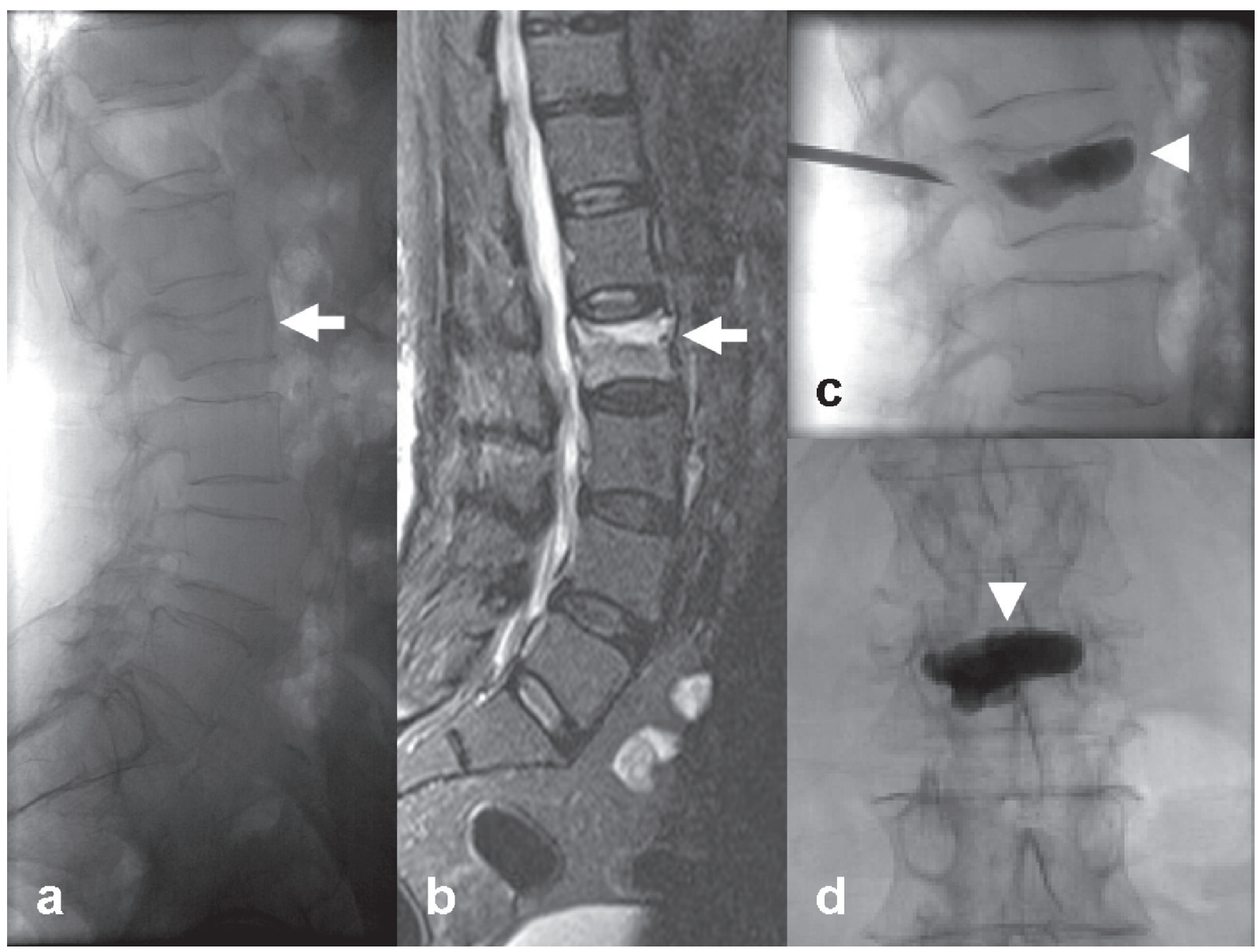

Figure 7 Example of percutaneous vertebroplasty for lumbar osteoporotic fracture. A 72-year-old female patient with severe back pain. (a) Lateral lumbar X-ray demonstrates a fractured L2 vertebral body (white arrow) (b) High signal on STIR MR sequence due to bone edema, compatible with a recently onset osteoporotic fracture (white arrow) (c-d) Percutaneous unipedicular vertebroplasty and cement stabilization of the affected body (Optimed Vertebroplasty System, Pyramed, Esher, United Kingdom). A bone biopsy specimen was taken before cement injection (white arrowheads) to exclude any underlying malignancy. The patient experienced immediate post-operative pain relief and was ambulated the following day.

for osteoporosis, infection, myelopathy related to retropulsed fragments and uncorrected coagulopathy. ${ }^{88}$

Complications are more common in the treatment of metastatic compared to osteoporotic disease. The incidence of serious complications has been reported at $0.9 \%$ including severe cement leakage or neurological symptoms requiring surgery ${ }^{83}$ Cement leakage is in fact a common phenomenon (41\%) and sometimes a small amount may indicate that optimal filling of the vertebral body has been achieved. The incidence of cement embolism is thought to be very low $(0.1 \%)$ and symptomatic cases are confined to case reports. ${ }^{89}$ The risk of fracture to adjacent vertebral bodies following vertebroplasty is also recognized. Although the absolute risk is unclear the increased risk may be as high as 5 -fold.${ }^{90}$ Kyphoplasty, which reduces the degree of deformity, may help to reduce this risk. Pneumothorax and paraspinal haematoma are further risks when the procedure is performed in the thoracic spine. ${ }^{87}$
These procedures are characterized by an immediate analgesic effect ${ }^{91}$ with the large majority experiencing pain relief within hours of the procedure. ${ }^{82}$ Despite this, the cause for pain relief is poorly understood. Bone cement (polymethylmethylacrylate [PMMA]), which achieves $90 \%$ of its ultimate strength within one hour of injection, ${ }^{92}$ may immobilize fracture fragments and have a heat effect on nerve endings. ${ }^{83}$ However no correlation has been found between the amount of cement injected or indeed the degree of vertebral body height restored and pain relief. ${ }^{93}$ Many studies now support the use of these techniques although long-term studies and head-to-head randomized clinical trials are still lacking. ${ }^{94}$ Short- to mid-term follow up has shown a 90\% improvement in pain levels 18 months following vertebroplasty for osteoporotic fractures. ${ }^{92}$ A study of 173 patients with osteoporotic vertebral compression fractures found significant pain reduction immediately following the procedure and $82 \%$ reported marked to complete resolution of 
original symptoms at 2 years independent of whether single or multiple levels were treated. ${ }^{95}$ A study of 112 patients with up to 3 years follow up found significantly less analgesia used and a high rate of patient satisfaction. ${ }^{96}$ Of particular relevance to the elderly, one study has demonstrated $69 \%$ of nonambulatory patients becoming ambulatory following vertebroplasty due to significant pain relief. ${ }^{91}$ A review of the literature on the treatment of metastases and debilitating pain has demonstrated pain relief in $50 \%-97 \%$ of patients following vertebroplasty. This outcome is similar to the ones reported for surgical treatment. ${ }^{87,97}$ A pooled analysis of 19 studies has demonstrated a $67.9 \%$ reduction in reported pain using a visual analogue scale following vertebroplasty for all causes. ${ }^{83}$ A systematic comparative review of vertebroplasty and kyphoplasty suggests that both provide similar pain relief although kyphoplasty may have benefits in functionality and quality of life with lower rates of cement leakage, and less neurologic and pulmonary complications. ${ }^{85}$

\section{Conclusion}

Minimally invasive interventional radiological procedures may be applied for the curative or palliative treament of a variety of disorders in the elderly population. In comparison to surgery, they are related with significantly less mortality and morbidity, while being equally effective. This is of extreme importance in the setting of elderly patients suffering from multiple comorbidities and associated risk factors. Physicians actively involved in the care of elderly patients, especially octogenarians, need to be aware of the range of image-guided percutaneous treatment options including their indications, efficacy, results and potential complications.

\section{Disclosure}

The authors report no conflicts of interest in this work.

\section{References}

1. Sabharwal T, Fotiadis N, Adam A. Modern trends in interventional radiology. Br Med Bull. 2007;81-82:167-182.

2. Liapi E, Geschwind JF. Transcatheter and ablative therapeutic approaches for solid malignancies. J Clin Oncol. 2007;25(8):978-986.

3. Blommers E, Klimek M, Klein J, Noordzij PG. [Perioperative care for the older patient]. Ned Tijdschr Geneeskd. 2008;152(27):1513-1517.

4. O'Connor OJ, Buckley JM, Maher MM. Interventional Radiology in oncology. Cancer Treat Res. 2008;143:493-511.

5. Young N, Chi KK, Ajaka J, McKay L, O’Neill D, Wong KP. Complications with outpatient angiography and interventional procedures. Cardiovasc Intervent Radiol. 2002;25(2):123-126.

6. Lüttje D, Maio G, Wedding U. [The situation of elderly patients] Onkologie. 2008;31(Suppl 3):1-5.

7. Devesa SA, Hunter CP. The burden of cancer in the elderly. In: Hunter CP, Johnson KA, Muss HB, editors. Cancer in the elderly. Informa Health Care; 2000. p. 2-6.
8. Progressreport.cancer.gov. Cancer Trends Progress Report - 2007 Update, National Cancer Institute, NIH, DHHS, Bethesda, MD, December 2007. Cited Oct 10, 2008. Available from http://progressreport.cancer.gov/.

9. McGahan JP, Browning PD, Brock JM, Tesluk H. Hepatic ablation using radiofrequency electrocautery. Invest Radiol. 1990;25(3):267-270.

10. Beland M, Mueller PR, Gervais DA. Thermal ablation in interventional oncology. Semin Roentgenol. 2007;42(3):175-190.

11. Gervais DA, McGovern FJ, Arellano RS, McDougal WS, Mueller PR. Radiofrequency ablation of renal cell carcinoma: part 1, Indications, results, and role in patient management over a 6-year period and ablation of 100 tumors. AJR Am J Roentgenol. 2005;185(1):64-71.

12. Machi J, Oishi AJ, Sumida K, et al. Long-term outcome of radiofrequency ablation for unresectable liver metastases from colorectal cancer: evaluation of prognostic factors and effectiveness in first- and second-line management. Cancer J. 2006;12(4):318-326.

13. Garrean S, Hering J, Saied A, Helton WS, Espat NJ. Radiofrequency ablation of primary and metastatic liver tumors: a critical review of the literature. Am J Surg. 2008;195(4):508-520.

14. Decadt B, Siriwardena AK. Radiofrequency ablation of liver tumours: systematic review. Lancet Oncol. 2004;5(9):550-560.

15. Lencioni R, Cioni D, Crocetti L, et al. Early-stage hepatocellular carcinoma in patients with cirrhosis: long-term results of percutaneous image-guided radiofrequency ablation. Radiology. 2005;234(3):961-967.

16. Gillams AR. Image guided tumour ablation. Cancer Imaging. 2005;5:103-109.

17. Machi J, Uchida S, Sumida K, et al. Ultrasound-guided radiofrequency thermal ablation of liver tumors: percutaneous, laparoscopic, and open surgical approaches. J Gastrointest Surg. 2001;5(5):477-489.

18. Fotiadis NI, Sabharwal T, Morales JP, Hodgson DJ, O'Brien TS, Adam A. Combined percutaneous radiofrequency ablation and ethanol injection of renal tumours: midterm results. Eur Urol. 2007;52(3):777-784.

19. Lewin JS, Nour SG, Connell CF, et al. Phase II clinical trial of interactive MR imaging-guided interstitial radiofrequency thermal ablation of primary kidney tumors: initial experience. Radiology. 2004;232(3):835-845.

20. Grunberg SM, Bibawi SE. Lung Cancer. In: Hunter CP, Johnson KA, Muss HB, editors. Cancer in the elderly. Informa Health Care; 2000. p. 345-349.

21. Zhu JC, Yan TD, Morris DL. A systematic review of radiofrequency ablation for lung tumors. Ann Surg Oncol. 2008;15(6):1765-1774.

22. Haasbeek CJ, Senan S, Smit EF, Paul MA, Slotman BJ, Lagerwaard FJ. Critical review of nonsurgical treatment options for stage I non-small cell lung cancer. Oncologist. 2008;13(3):309-319.

23. Mercadante S. Malignant bone pain: pathophysiology and treatment. Pain. 1997;69(1-2):1-18.

24. Callstrom MR, Charboneau JW. Image-guided palliation of painful metastases using percutaneous ablation. Tech Vasc Interv Radiol. 2007;10(2):120-131.

25. Gangi A, Dietemann JL, Schultz A, Mortazavi R, Jeung MY, Roy C. Interventional radiologic procedures with $\mathrm{CT}$ guidance in cancer pain management. Radiographics. 1996;16(6):1289-1306.

26. Sabharwal T, Salter R, Adam A, Gangi A. Image-guided therapies in orthopedic oncology. Orthop Clin North Am. 2006;37(1):105-112.

27. Callstrom MR, Charboneau JW, Goetz MP, et al. Image-guided ablation of painful metastatic bone tumors: a new and effective approach to a difficult problem. Skeletal Radiol. 2006;35(1):1-15.

28. Callstrom MR, Atwell TD, Charboneau JW, et al. Painful metastases involving bone: percutaneous image-guided cryoablation - prospective trial interim analysis. Radiology. 2006;241(2):572-580.

29. O'Connor OJ, Buckley JM, Maher MM. Interventional Radiology in oncology. Cancer Treat Res. 2008;143:493-511.

30. Burstein HJ, Mayer RJ. Gastronintestinal Cancer. In: Hunter CP, Johnson KA, Muss HB, editors. Cancer in the elderly. Informa Health Care; 2000. p. 325-328. 
31. Sabharwal T, Morales JP, Irani FG, Adam A; CIRSE: Cardiovascular and Interventional Radiological Society of Europe. Quality improvement guidelines for placement of esophageal stents. Cardiovasc Intervent Radiol. 2005;28(3):284-288.

32. Sabharwal T, Irani FG, Adam A; Cardiovascular and Interventional Radiological Society of Europe. Quality assurance guidelines for placement of gastroduodenal stents. Cardiovasc Intervent Radiol. 2007;30(1):1-5.

33. Sabharwal T, Morales JP, Salter R, Adam A. Esophageal cancer: self-expanding metallic stents. Abdom Imaging. 2005;30:456-464.

34. Lowe AS, Sheridan MB. Esophageal stenting. Semin Intervent Rad. 2004;21(3):157-166.

35. Lee $\mathrm{SH}$. The role of oesophageal stenting in the non-surgical management of oesophageal strictures. Br J Radiol. 2001;74(886):891-900.

36. Watson A. Self-expanding metal oesophageal endoprostheses: which is best? Eur J Gastroenterol Hepatol. 1998;10(5):363-365.

37. Wang MQ, Sze DY, Wang ZP, Wang ZQ, Gao YA, Dake MD. Delayed complications after esophageal stent placement for treatment of malignant esophageal obstructions and esophagorespiratory fistulas. J Vasc Interv Radiol. 2001;12(4):465-474.

38. Kirkham AP, Ho SG. Radiological interventions in gastrointestinal and urological oncology. Semin Roentgenol. 2007;42(3):191-204.

39. Given MF, Lyon SM, Lee MJ. The role of the interventional radiologist in enteral alimentation. Eur Radiol. 2004;14(1):38-47.

40. Lopera JE, Brazzini A, Gonzales A, Castaneda-Zuniga WR. Gastroduodenal Stent Placement: Current Status. Radiographics. 2004;24(6):1561-1573.

41. Zollikofer CL, Jost R, Schoch E, Decurtins M. Gastrointestinal stenting. Eur Radiol. 2000;10(2):329-341.

42. Dormann A, Meisner S, Verin N, Wenk Lang A. Self expanding metal stents for gastroduodenal malignancies: systematic review of their clinical effectiveness. Endoscopy. 2004;36(6):543-550.

43. Sebastian S, Johnston S, Geoghegan T, Torreggiani W, Buckley M. Pooled analysis of the efficacy and safety of self-expanding metal stenting in malignant colorectal obstruction. Am J Gastroenterol. 2004;99(10):2051-2057.

44. Govindarajan A, Naimark D, Coburn NG, Smith AJ, Law CH. Use of colonic stents in emergent malignant left colonic obstruction: A Markov Chain Monte Carlo decision analysis. Dis Colon Rectum. 2007;50(11):1811-1824.

45. Dharmadhikari R, Nice C. Complications of colonic stenting: a pictorial review. Abdom Imaging. 2008;33(3):278-284.

46. Xinopoulos D, Dimitroulopoulos D, Theodosopoulos T, et al. Stenting or stoma creation for patients with inoperable malignant colonic obstruction? Results of a study and cost effectiveness analysis. Surg Endosc. 2004;18(3):421-426.

47. Binkert CA, Ledermann H, Jost R, Saurenmann P, Decurtins M, Zollikofer CL. Acute colonic obstruction: Clinical aspects and cost-effectiveness of preoperative and palliative treatment with self-expanding metallic stents - a preliminary report. Radiology. 1998;206(1):199-204.

48. Khot UP, Lang AW, Murali K, Parker MC. Systematic review of the efficacy and safety of colorectal stents. Br J Surg. 2002;89(9):1096-1102.

49. Aitken DG, Horgan AF. Endoluminal insertion of colonic stents. Surg Oncol. 2007;16(1):59-63.

50. Zollikofer CL. Stenting of upper and lower GI tract obstruction. Acta Gastroenterol Belg. 2000;63(2):165-168.

51. Shim CS, Cho JY, Jung IS, et al. Through the scope double colonic stenting in the management of inoperable proximal malignant colonic obstruction: a pilot study. Endoscopy. 2004;36(5):426-431.

52. Saito Y, Imamura H. Airway stenting. Surg Today. 2005; 35(4):265-270.

53. Walser EM. Stent placement for tracheobronchial disease. Eur J Radiol. 2005;55(3):321-330.

54. Shin JH, Song HY, Shim TS. Management of tracheobronchial strictures. Cardiovasc Intervent Radiol. 2004;27(4):314-324.

55. Zakaluzny SA, Lane JD, Mair EA. Complications of tracheobronchial airway stents. Otolaryngol Head Neck Surg. 2003;128(4):478-488.
56. Makris D, Marquette CH.Tracheobronchial stenting and central airway replacement. Curr Opin Pulm Med. 2007;13(4):278-283.

57. Henebiens M, Vahl A, Koelemay MJ. Elective surgery of abdominal aortic aneurysms in octogenarians: a systematic review. J Vasc Surg. 2008;47(3):676-681.

58. Nienaber CA, Kische S, Ince H. Thoracic aortic stent-graft devices: problems, failure modes, and applicability. Semin Vasc Surg. 2007;20(2):81-89.

59. Kpodonu J, Preventza O, Ramaiah VG, et al. Endovascular repair of the thoracic aorta in octogenarians. Eur J Cardiothorac Surg. 2008;34(3):630-634.

60. Parodi JC, Palmaz JC, Barone HD. Transfemoral intraluminal graft implantation for abdominal aortic aneurysms. Ann Vasc Surg. 1991;5(6):491-499.

61. Lange C, Leurs LJ, Buth J, Myhre HO, EUROSTAR collaborators. Endovascular repair of abdominal aortic aneurysm in octogenarians: an analysis based on EUROSTAR data. J Vasc Surg. 2005;42(4):624-630.

62. Ricotta JJ 2nd, Oderich GS. Fenestrated and branched stent grafts. Perspect Vasc Surg Endovasc Ther. 2008;20(2):174-189.

63. Dake MD, Miller DC, Semba CP, Mitchell RS, Walker PJ, Liddell RP. Transluminal placement of endovascular stent-grafts for the treatment of descending thoracic aortic aneurysms. $N$ Engl J Med. 1994;331(26):1729-1734.

64. Lee JT, White RA. Current status of thoracic aortic endograft repair. Surg Clin North Am. 2004;84(5):1295-1318.

65. Swee W, Dake MD. Endovascular management of thoracic dissections. Circulation. 2008;117(11):1460-1473.

66. Kern JA, Matsumoto AH, Tribble CG, et al. Thoracic aortic endografting is the treatment of choice for elderly patients with thoracic aortic disease. Ann Surg. 2006;243(6):815-823.

67. Hirsch AT, Haskal ZJ, Hertzer NR, et al. ACC/AHA guidelines for the management of patients with peripheral arterial disease (lower extremity, renal, mesenteric, and abdominal aortic): a collaborative report from the American Associations for Vascular Surgery/Society for Vascular Surgery, Society for Cardiovascular Angiography and Interventions, Society for Vascular Medicine and Biology, Society of Interventional Radiology, and the ACC/AHA Task Force on Practice Guidelines (writing committee to develop guidelines for the management of patients with peripheral arterial disease) - summary of recommendations. J Vasc Interv Radiol. 2006;17(9):1383-1398.

68. Siablis D, Karnabatidis D, Katsanos K, Diamantopoulos A, Christeas N, Kagadis GC. Infrapopliteal application of paclitaxel-eluting stents for critical limb ischemia: midterm angiographic and clinical results. J Vasc Interv Radiol. 2007;18(11):1351-1361.

69. Tsetis D, Belli AM. The role of infrapopliteal angioplasty. Br J Radiol. 2004;77(924):1007-1015

70. Norgren L, Hiatt WR, Dormandy JA, Nehler MR, Harris KA, Fowkes FG, Rutherford RB; TASC II Working Group. Inter-society consensus for the management of peripheral arterial disease. Int Angiol. 2007;26(2):81-157.

71. Brem H, Tomic-Canic M. Cellular and molecular basis of wound healing in diabetes. J Clin Invest. 2007;117(5):1219-1222.

72. Siablis D, Kraniotis P, Karnabatidis D, Kagadis GC, Katsanos K, Tsolakis J. Sirolimus-eluting versus bare stents for bailout after suboptimal infrapopliteal angioplasty for critical limb ischemia: 6-month angiographic results from a nonrandomized prospective single-center study. J Endovasc Ther. 2005;12(6):685-695.

73. Siablis D, Karnabatidis D, Katsanos K, et al. Sirolimus-eluting versus bare stents after suboptimal infrapopliteal angioplasty for critical limb ischemia: enduring 1-year angiographic and clinical benefit. $J$ Endovasc Ther. 2007;14(2):241-250.

74. Dick P, Barth B, Mlekusch W, et al. Complications After peripheral vascular interventions in octogenarians. J Endovasc Ther. 2008;15(4):383-389.

75. Kandarpa K, Becker GJ, Hunink MG, et al. Transcatheter interventions for the treatment of peripheral atherosclerotic lesions: part I. $J$ Vasc Interv Radiol. 2001;12(6):683-695. 
76. Romiti M, Albers M, Brochado-Neto FC, Durazzo AE, Pereira CA, De Luccia N. Meta-analysis of infrapopliteal angioplasty for chronic critical limb ischemia. J Vasc Surg. 2008;47(5):975-981.

77. Ballard JL, Mills JL Sr. Surgical management of critical limb ischemia. Tech Vasc Interv Radiol. 2005;8(4):169-174.

78. Scheinert D, Ulrich M, Scheinert S, et al. Comparison of sirolimus-eluting vs bare-metal stents for the treatment of infrapopliteal obstructions. EuroIntervention. 2006;2(2):169-174.

79. Bosiers M, Hart JP, Deloose K, Verbist J, Peeters P. Endovascular therapy as the primary approach for limb salvage in patients with critical limb ischemia: Experience with 443 Infrapopliteal Procedures. Vascular. 2006;14(2):63-69.

80. Commeau P, Barragan P, Roquebert PO. Sirolimus for below the knee lesions: mid-term results of SiroBTK study. Catheter Cardiovasc Interv. 2006;68(5):793-798.

81. Bosiers M, Deloose K, Verbist J, Peeters P. Percutaneous transluminal angioplasty for treatment of "below-the-knee" critical limb ischemia: early outcomes following the use of sirolimus-eluting stents. J Cardiovasc Surg (Torino). 2006;47(2):171-176.

82. Lemke DM. Vertebroplasty and kyphoplasty for treatment of painful osteoporotic compression fractures. J Am Acad Nurse Pract. 2005;17(7):268-276.

83. Hochmuth K, Proschek D, Schwarz W, Mack M, Kurth AA, Vogl TJ. Percutaneous vertebroplasty in the therapy of osteoporotic vertebral compression fractures: a critical review. Eur Radiol. 2006;16(5):998-1004.

84. Crandall D, Slaughter D, Hankins PJ, Moore C, Jerman J. Acute versus chronic vertebral compression fractures treated with kyphoplasty: early results. Spine J. 2004;4(4):418-424.

85. Taylor RS, Taylor RJ, Fritzell P. Balloon kyphoplasty and vertebroplasty for vertebral compression fractures: a comparative systematic review of efficacy and safety. Spine. 2006;31(23):2747-2255.

86. Taylor RS, Fritzell P, Taylor RJ. Balloon kyphoplasty in the management of vertebral compression fractures: an updated systematic review and meta-analysis. Eur Spine J. 2007;16(8):1085-1100.
87. Jakobs TF, Trumm C, Reiser M, Hoffmann RT. Percutaneous vertebroplasty in tumoral osteolysis. Eur Radiol. 2007;17(8):2166-2175.

88. McGraw JK, Cardella J, Barr JD, et al. Society of Interventional Radiology quality improvement guidelines for percutaneous vertebroplasty. J Vasc Interv Radiol. 2003;14(7):827-831.

89. Yoo KY, Jeong SW, Yoon W, Lee J. Acute respiratory distress syndrome associated with pulmonary cement embolism following percutaneous vertebroplasty with polymethylmethacrylate. Spine. 2004;29(14):294-297.

90. Burton AW, Mendel E. Vertebroplasty and kyphoplasty. Pain Physician. 2003;6(3):335-341.

91. Alvarez L, Pérez-Higueras A, Quiñones D, Calvo E, Rossi RE. Vertebroplasty in the treatment of vertebral tumors: postprocedural outcome and quality of life. Eur Spine J. 2003;12(4):356-360.

92. Deramond H, Depriester C, Toussaint P, Galibert P. Percutaneous vertebroplasty. Semin Musculoskelet Radiol. 1997;1(2):285-296.

93. Prather H, Watson JO, Gilula LA. Nonoperative management of osteoporotic vertebral compression fractures. Injury. 2007;(38 Suppl 3):S40-S48.

94. Mathis JM, Barr JD, Belkoff SM, Barr MS, Jensen ME, Deramond H. Percutaneous vertebroplasty: a developing standard of care for vertebral compression fractures. AJNR Am J Neuroradiol. 2001;22(2):373-381.

95. Singh AK, Pilgrim TK, Gilula LA. Osteoporotic compression fractures: outcomes after single- versus multiple-level percutaneous vertebroplasty. Radiology. 2006;238(1):211-220.

96. Voormolen MH, Lohle PN, Lampmann LE, et al. Prospective clinical follow-up after percutaneous vertebroplasty in patients with painful osteoporotic vertebral compression fractures. J Vasc Interv Radiol. 2006;17(8):1313-1320.

97. Weigel B, Maghsudi M, Neumann C, Kretschmer R, Müller FJ, Nerlich M. Surgical management of symptomatic spinal metastases. Postoperative outcome and quality of life. Spine. 1999;24(21):2240-2246. 
